\title{
The potential contribution of yellow cassava to dietary nutrient adequacy of primary-school children in Eastern Kenya; the use of linear programming
}

\author{
Elise F Talsma ${ }^{1,2, *}$, Karin J Borgonjen-van den Berg ${ }^{1}$, Alida Melse-Boonstra ${ }^{1}$, Eva V Mayer ${ }^{1}$, \\ Hans Verhoef ${ }^{3,4,5}$, Ayşe Y Demir ${ }^{6}$, Elaine L Ferguson', Frans J Kok ${ }^{1}$ and Inge D Brouwer ${ }^{1}$ \\ 'Division of Human Nutrition, Wageningen University, Wageningen, The Netherlands: ${ }^{2}$ HarvestPlus, International \\ Center for Tropical Agriculture (CIAT), Km 17, Recta Cali-Palmira, Apartado Aéreo 6713, Cali, Colombia: ${ }^{3}$ Cell \\ Biology and Immunology Group, Wageningen University, Wageningen, The Netherlands: ${ }^{4}$ Medical Research \\ Council (MRC) International Nutrition Group, London School of Hygiene \& Tropical Medicine, London, UK: ${ }^{5}$ MRC \\ Keneba, The Gambia: ${ }^{6}$ Laboratory for Clinical Chemistry, Meander Medical Centre, Amersfoort, The Netherlands: \\ ${ }^{7}$ Faculty of Epidemiology and Population Health, Department of Population Health, London School of Hygiene \& \\ Tropical Medicine, London, UK
}

Submitted 1 February 2017: Final revision received 14 July 2017: Accepted 7 August 2017: First published online 2 0ctober 2017

\begin{abstract}
Objective: Introduction of biofortified cassava as school lunch can increase vitamin A intake, but may increase risk of other deficiencies due to poor nutrient profile of cassava. We assessed the potential effect of introducing a yellow cassava-based school lunch combined with additional food-based recommendations (FBR) on vitamin A and overall nutrient adequacy using Optifood (linear programming tool). Design: Cross-sectional study to assess dietary intakes ( $24 \mathrm{~h}$ recall) and derive model parameters (list of foods consumed, median serving sizes, food and food (sub)group frequency distributions, food cost). Three scenarios were modelled, namely daily diet including: (i) no school lunch; (ii) standard $5 \mathrm{~d}$ school lunch with maize/beans; and (iii) $5 \mathrm{~d}$ school lunch with yellow cassava. Each scenario and scenario 3 with additional FBR were assessed on overall nutrient adequacy using recommended nutrient intakes (RNI).

Setting: Eastern Kenya.

Subjects: Primary-school children ( $n$ 150) aged 7-9 years.

Results: Best food pattern of yellow cassava-based lunch scenario achieved $100 \%$ RNI for six nutrients compared with no lunch (three nutrients) or standard lunch (five nutrients) scenario. FBR with yellow cassava and including small dried fish improved nutrient adequacy, but could not ensure adequate intake of fat ( $52 \%$ of average requirement), riboflavin ( $50 \% \mathrm{RNI})$, folate $(59 \% \mathrm{RNI})$ and vitamin $\mathrm{A}$ (49\% RNI).

Conclusions: Introduction of yellow cassava-based school lunch complemented with FBR potentially improved vitamin A adequacy, but alternative interventions are needed to ensure dietary adequacy. Optifood is useful to assess potential contribution of a biofortified crop to nutrient adequacy and to develop additional FBR to address remaining nutrient gaps.
\end{abstract}

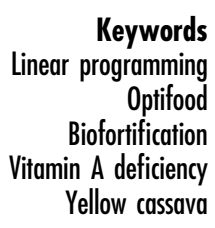

Biofortification of staple foods is recognized as a sustainable food-based approach to reduce micronutrient deficiencies as it has the potential to substantially increase the micronutrient intakes of a population ${ }^{(1)}$. Biofortified yellow cassava, developed through conventional plantbreeding techniques, is a new staple food that is similar in use and nutritional content to white cassava but additionally contains substantially higher amounts of provitamin $\mathrm{A}^{(2)}$. Yellow cassava could potentially increase vitamin A intake and reduce vitamin A deficiency, especially in remote rural areas where other interventions face challenges to reach people in need of vitamin $\mathrm{A}^{(3,4)}$.

Although yellow cassava is an excellent source for provitamin A and energy, it is known to be generally poor in other nutrients such as $\mathrm{Fe}$ and $\mathrm{Zn}^{(5)}$. Children whose diets consist largely of cassava may be vulnerable to micronutrient deficiencies ${ }^{(6)}$. As diets in resource-poor environments often lack multiple micronutrients ${ }^{(7)}$, the introduction of yellow cassava, even when only the replacement of white cassava is targeted, will require 
additional food-based dietary adaptations to fill the existing nutrient gaps in the diet. Also, yellow cassava might displace other staple foods in the diet, so promoting its consumption may inadvertently have a negative impact on dietary adequacy.

Optifood, a software program based on linear programming, was developed to formulate affordable, population-specific, food-based recommendations (FBR) based on current dietary practices and costs of food ${ }^{(8)}$. As these FBR are developed to resemble the local diet as closely as possible, they are more likely to be followed than more general guidelines that may deviate from local habits. This mathematical modelling approach provides an objective method to predict, for example, whether fortification, supplementation or special complementary food products are needed to ensure dietary adequacy for high-risk populations and the extent to which these measures might contribute to its achievement ${ }^{(9,10)}$. To our knowledge, Optifood has not yet been used to inform biofortification programmes planning to promote the consumption of a biofortified crop with elevated levels of a single nutrient within a set of dietary recommendations. The advantages of using this mathematical modelling approach are that it objectively determines: (i) whether promoting a biofortified food, to improve dietary adequacy of one nutrient, might affect overall dietary adequacy by replacing important food sources of other nutrients; and (ii) the optimal set of FBR that need to be promoted in addition to the biofortified crop to ensure dietary adequacy at an affordable cost.

School feeding is an important and widespread educational intervention globally involving approximately 370 million school-aged children ${ }^{(11)}$, an often-neglected group, providing an opportunity for micronutrient interventions in a controlled environment ${ }^{(12)}$. School feeding programmes are designed to support education and food security of children living in poverty, by increasing enrolment and reducing absenteeism and dropouts, and contributing to their learning through avoiding short-term hunger ${ }^{(13)}$. However, less attention is given to reducing or preventing micronutrient deficiencies ${ }^{(14)}$. In Kenya, school feeding programmes provide a school lunch generally comprised of a mixture of cooked maize and beans ${ }^{(15)}$, referred to as githeri, a common dish regularly consumed in households. In Eastern Kenya, however, rural schoolchildren are documented to have high levels of anaemia, stunting and inadequate intakes of many key nutrients in addition to vitamin $\mathrm{A}^{(16)}$. Murphy et al. showed that githeri as a school lunch did not improve the dietary quality and micronutrient intakes of schoolchildren in Eastern Kenya ${ }^{(17)}$. The introduction of yellow cassava, currently grown experimentally in Eastern Kenya, into the school feeding programme could improve the vitamin A intakes of schoolchildren but additional food-based dietary recommendations would be needed to achieve overall nutrient adequacy of the diet given the nutrient profile of cassava.
In the present study, secondary dietary intake data collected in the framework of a yellow cassava efficacy trial $^{(18)}$ were used in Optifood to: (i) evaluate whether including yellow cassava in the school lunch would potentially improve vitamin A adequacy without having a negative effect on overall dietary adequacy compared with no school lunch or a standard school lunch; and (ii) identify additional FBR needed in a yellow cassavabased school lunch programme to improve adequacy of nutrients other than vitamin A at lowest cost.

\section{Materials and methods}

\section{Study design}

The present study was based on cross-sectional dietary intake data collected as part of an 18-week randomized controlled trial on the efficacy of yellow cassava in improving vitamin A status in primary-school children ${ }^{(18)}$. In that trial, cassava was served as a mid-morning snack of boiled white or yellow cassava to children aged 5-13 years from May to November 2012. The trial also provided a school lunch made of a mix of cooked maize and beans. Cross-sectional dietary intake data were collected to quantify food intake in and outside the school and used to define inputs to model (using linear programming) three scenarios for a $7 \mathrm{~d}$ best diet, namely a daily diet including: (i) no school lunch; (ii) a standard $5 \mathrm{~d}$ school lunch with cooked maize and beans; or (iii) a $5 \mathrm{~d}$ school lunch of cooked yellow cassava. The yellow cassava-based school lunch scenario was further optimized using nutrient-dense foods.

The original study was registered (clinicaltrials.gov: NCT01614483), approved by ethical committees at Kenyatta National Hospital in Nairobi, Kenya and Wageningen University in the Netherlands, and written consent was obtained from parents and children.

\section{Participants}

The original trial involved 342 children ( $5-13$ years old) in three primary schools in Kibwezi District, Eastern Province, Kenya, who were selected by screening and ranking according to serum retinol-binding protein concentration and those at the lowest end of the distribution were selected for the trial. For the present modelling study, we selected all dietary intake data available of children between 7 and 9 years of age $(n 150)$ as they represented the largest age group for which FBR could be made.

\section{Nutritional status assessment}

\section{Blood sample collection}

All venous blood samples were obtained from fasted children at the start of the trial by venepuncture. Samples for retinol analyses were shielded from light and processed under subdued light conditions. All blood samples were stored at $2-8^{\circ} \mathrm{C}$ until centrifuging and in liquid 
nitrogen $\left(-196^{\circ} \mathrm{C}\right)$ in Kenya, and at $-80^{\circ} \mathrm{C}$ during transport to and storage at the laboratory of the Division of Human Nutrition in Wageningen, the Netherlands.

\section{Blood analyses}

Concentrations of retinol were measured by HPLC and described in detail elsewhere ${ }^{(18)}$. Serum concentrations of C-reactive protein, $\alpha_{1}$-acid glycoprotein, serum ferritin, serum soluble transferrin receptor, serum vitamin $\mathrm{B}_{12}$ and serum Zn were measured at the Meander Medical Hospital, Amersfoort, the Netherlands on a Beckman Coulter UniCel DxC 880i analyser as per manufacturer's instructions. Hb was measured using a Celltac- $\alpha$ automated haematology analyser (MEK-6410K) in Makindu Hospital, Kenya, as per manufacturer's instructions.

\section{Nutritional deficiency cut-off levels}

Vitamin A deficiency: serum retinol concentration $<0.7 \mu \mathrm{mol} / \mathrm{l}^{(19)} ; \mathrm{Zn}$ deficiency: serum $\mathrm{Zn}$ concentration $<9.9 \mu \mathrm{mol} / \mathrm{l}^{(20)}$; vitamin $\mathrm{B}_{12}$ deficiency: mild, serum vitamin $\mathrm{B}_{12}$ concentration $<133 \mathrm{pmol} / \mathrm{l}$ and moderate or severe, serum vitamin $\mathrm{B}_{12}$ concentration $<107 \mathrm{pmol} / \mathrm{l}^{(21)}$; anaemia: $\mathrm{Hb}$ concentration $<115 \mathrm{~g} / \mathrm{l}^{(22)}$; Fe deficiency: serum ferritin concentration $<15 \mu \mathrm{g} / \mathrm{l}^{(22)}$.

\section{Weight and beight}

Weight and height were measured at baseline according to WHO guidelines ${ }^{(23)}$ using a mechanical floor scale and a portable stadiometer (Seca, Hamburg, Germany). Anthropometric indices were calculated using WHO ANTHROplus software version 3.2.2 (www.who.int/childgrowth/ software/en/). Stunting was defined as $Z$-score for heightfor-age less than -2 .

\section{Inflammation}

Inflammation was defined as C-reactive protein $>5 \mathrm{mg} / \mathrm{l}$ and/or serum $\alpha_{1}$-acid glycoprotein concentration $>1 \mathrm{~g} / \mathrm{l}^{(24)}$.

\section{Dietary intake assessment}

Dietary intakes of children out-of-school were assessed using a quantitative multi-pass $24 \mathrm{~h}$ recall ${ }^{(25)}$ with all days evenly distributed over the week. These data were collected, during a home visit in October 2012, by welltrained interviewers in weeks 13 to 16 of the trial. Primary caregivers, in the presence of the child, were asked to recall all the foods and drinks consumed in and outside the home (except for the school lunch) by their child during the preceding day and to describe ingredients and cooking methods of any mixed dishes. Duplicate amounts of all foods or beverages consumed or of ingredients used in the preparation of mixed dishes consumed were weighed to the nearest $2 \mathrm{~g}$ using a Soehnle electronic kitchen scale. When duplicates were not available in the household, amounts were estimated in household units, in volumes, as their general sizes (small, medium or large), or as their monetary value equivalents. The total volume of each (mixed) dish cooked at the respondents' household and the volume of this dish specifically consumed by the child were measured to determine the proportion of the dish consumed by the child. This proportion was multiplied by the total amount of ingredients used in the preparation of the dish to determine the amount of ingredients consumed by the child. Standard recipes were generated to estimate grams of ingredients consumed from mixed dishes eaten outside the home by averaging three recipes of different vendors in the local area ${ }^{(26)}$. Conversion factors were developed to convert household units, volumes, sizes and monetary values to their gram weight equivalents. Food price data were also collected from three different markets/kiosks to calculate, for each food, its mean price per $100 \mathrm{~g}$ of edible food.

Cassava intake in the schools was recorded daily as the difference in the weight of the plate of each child before and after eating during the 18 -week intervention period and median intake was calculated. Pro-vitamin A concentration of the yellow and white cassava was analysed $^{(18)}$. To estimate the average serving size of the maize and beans dish given at schools, the cooks ( $n$ 3) were asked to provide a standard portion per school and median portion size was calculated.

\section{Data preparation and analysis for Optifood}

\section{Data preparation}

The $24 \mathrm{~h}$ recall data were organized with the nutrient calculation system Compl-eat version 1.0 (Wageningen University, Wageningen, the Netherlands) and the model parameters were defined by using Microsoft ${ }^{\circledR}$ Excel 2010, the statistical software package IBM SPSS Statistics version 21 and Microsoft ${ }^{\circledR}$ Access 2010. These parameters included: a list of non-condiment foods consumed by $\geq 5 \%$ of the children; the serving size of each food defined as median serving size for all children who had consumed it; and minimum and maximum number of servings per week, for each food group and food subgroup, defined as the 5 th and 95th percentiles, respectively, of serve counts. Average number of servings per week for each food group was defined as the 50th percentile. Maximum number of servings per individual food within a food subgroup was estimated based on the percentage of children consuming that food. For the school lunch with yellow cassava and with maize and beans, the minimum and maximum number of servings per week were set at five, assuming these foods would be provided as school lunch on $5 \mathrm{~d}$ / week. Prices per $100 \mathrm{~g}$ of edible food were used to estimate the average and 75 th percentile cost of the observed daily diet. All modelled diets had to meet (and not exceed) the energy requirement for the target group, estimated using their mean body weight and the FAO/WHO/United Nations University algorithm for estimating energy requirements $^{(27)}$. The FAO/WHO recommended nutrient intakes (RNI) were used for all nutrients, except $\mathrm{Zn}$, 
assuming $5 \%$ bioavailability for Fe $(18 \mathrm{mg} / \mathrm{d})^{(28,29)}$. For fat, average requirement of $30 \%$ of energy was used ${ }^{(30)}$. For Zn, the International Zinc Nutrition Consultative Group's RNI of $7 \mathrm{mg} / \mathrm{d}$ was used ${ }^{(31)}$ reflecting low bioavailability and representing the average of two age groups.

Nutrient intake calculations were based on a food composition table developed specifically for the present study, using the national food composition table of Kenya $^{(32)}$ as primary source complemented with data from food composition tables from South Africa ${ }^{(33)}$, Mali ${ }^{(34)}$, East Africa $^{(35)}$, the International Minilist ${ }^{(36)}$ and the US Department of Agriculture database ${ }^{(37)}$. US Department of Agriculture retention factors ${ }^{(38)}$ were applied to raw ingredients and foods to account for nutrient losses during food preparation. Pro-vitamin A and retinol were converted into retinol activity equivalents ${ }^{(39)}$. Pro-vitamin A concentrations in yellow cassava are predominantly in the form of $\beta$-carotene and total $\beta$-carotene concentration of boiled yellow and white cassava was used as analysed ${ }^{(18)}$. Conversion factors for $\beta$-carotene in cassava were conservatively assumed to be $7: 1$, based on a study in healthy Americans consuming yellow cassava ${ }^{(40)}$.

\section{Optifood analysis}

All analyses were carried out with Optifood version 4.0.4.0, an approach based on linear programming to design population-specific $\mathrm{FBR}^{(8)}$. Three dietary scenarios were modelled: (i) daily diet comprising foods consumed exclusively at or outside the home but not in school; (ii) daily diet complemented with a school lunch of cooked maize and beans; and (iii) daily diet complemented with a school lunch of cooked yellow cassava. Optifood's Modules 1-3 were used in the analyses. Module 1 was run to ensure model parameters were generating realistic diets. Subsequently, for each of the three dietary scenarios, Optifood's Module 2 was run to develop two best diets: one creating the best diet within the average food pattern and one creating the best diet deviating from the average food pattern but constrained by the minimum and maximum number of servings per week. The total number of nutrients achieving $100 \%$ of the RNI in the best diet deviating from the average food pattern ('best food pattern diet') were counted per scenario and compared between scenarios to determine whether including yellow cassava in the school lunch would affect overall dietary adequacy compared with no school lunch or a standard school lunch.

In Module 3, using the model parameters of the yellow cassava-based school lunch scenario, twenty-six different diets were modelled of which thirteen were diets with the maximized content of one of thirteen nutrients ('best-case scenario', selecting the high-nutrient-dense foods within each food group to verify the highest possible nutrient intake) and thirteen were diets with the minimized content of one of thirteen nutrients ('worst-case scenario', including the low-nutrient-dense foods per food group to verify the lowest possible nutrient intake). Module 3 was initially run without FBR constraints to identify problem nutrients. Problem nutrients are those that are $<100 \%$ of its RNI in the best-case scenario (i.e. when nutrient content is maximized). Next, food groups with weekly servings above zero in the Module 2 best food pattern diet, and individual foods contributing at least $5 \%$ to the intake of one of the nutrients, were selected. FBR were developed by incorporating the selected food groups and individual foods, individually and in combination, and were tested to identify sets of FBR that covered $>70 \%$ of the RNI for most nutrients. In the final phase of analyses, nutrient-dense foods that were consumed less frequently or in low quantities were incorporated in the FBR and tested in Module 3 to determine if they improved problem nutrient adequacy. These nutrient-dense foods were identified in two ways: (i) foods consumed by less than $5 \%$ of children that had a relatively high content of at least one of the problem nutrients; and (ii) foods consumed by $\geq 5 \%$ of children that contributed more than $20 \%$ to the intake of the problem nutrients and for which an increase in current number of servings per week was assumed to be feasible. In a last step, FBR incorporating selected nutrient-dense foods were tested in Module 3 separately. The set of recommendations (worst-case scenario) that achieved $>70 \%$ of the RNI for most nutrients but stayed below the 75 th percentile of daily diet cost was selected.

\section{Results}

\section{Baseline characteristics}

The children in our study were on average 8.5 years old with $27 \%$ being stunted (Table 1). Thirty per cent of the children suffered from vitamin A deficiency, but almost none were $\mathrm{Zn}$ deficient (3\%). Vitamin $\mathrm{B}_{12}$ status was in general low, with $58 \%$ of the children being mildly deficient and $37 \%$ being moderately or severely deficient. The prevalence of anaemia was only $6 \%$ but $36 \%$ of the children were Fe deficient. Inflammation affected $20 \%$ of our population.

\section{Food intake}

One hundred and fifty $24 \mathrm{~h}$ dietary recalls in total were used for data analysis and sixteen out of forty-eight non-condiment food items were consumed by more than $5 \%$ of the children (Table 2). Foods most commonly consumed were maize, both as whole grains and flour, beans, onions, tomatoes and oil. Serving sizes in the diet varied from $4 \mathrm{~g} / \mathrm{d}$ for onion to $165 \mathrm{~g} / \mathrm{d}$ for maize flour. Most of these sixteen foods had serving sizes $>10 \mathrm{~g} / \mathrm{d}$ ( $n$ 13, 81\%). White sugar, oil and onion were consumed in small portion sizes $(\leq 10 \mathrm{~g} / \mathrm{d})$. The median daily diet cost was 24 Kenyan Shilling (KES), ranging from 2 to 111 KES with the 75 th percentile estimated at $38 \mathrm{KES} / \mathrm{d}$. 
Table 1 Nutritional status indicators in the study population of primary-school children ( $n$ 150) aged 7-9 years, Eastern Kenya, May-November 2012

\begin{tabular}{|c|c|c|}
\hline & $\begin{array}{l}\text { Mean, } n \text { or } \\
\text { median }\end{array}$ & $\begin{array}{l}\text { SD, \% or } \\
\text { IQR }\end{array}$ \\
\hline \multicolumn{3}{|l|}{ Background characteristics } \\
\hline Age (years), mean and SD & 8.5 & 0.9 \\
\hline Sex $=$ girl, $n$ and $\%$ & 74 & 49 \\
\hline \multicolumn{3}{|l|}{ Anthropometrics } \\
\hline BMl-for-age ${ }^{*} Z$-score, mean and SD & $-1 \cdot 4$ & 0.9 \\
\hline 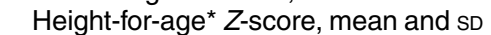 & $-1 \cdot 2$ & 1.0 \\
\hline Children being stunted ${ }^{*}, n$ and $\%$ & 41 & 27 \\
\hline \multicolumn{3}{|l|}{ Micronutrient markers } \\
\hline $\begin{array}{l}\text { Serum retinol concentration }(\mu \mathrm{mol} / \mathrm{l}) \text {, } \\
\text { mean and SD }\end{array}$ & $0 \cdot 81$ & $0 \cdot 18$ \\
\hline Vitamin A deficiency†, $n$ and $\%$ & 45 & 30 \\
\hline $\begin{array}{l}\text { Serum } \mathrm{Zn} \text { concentration }(\mu \mathrm{mol} / \mathrm{l}) \text {, } \\
\text { mean and SD }\end{array}$ & $13 \cdot 7$ & $2 \cdot 2$ \\
\hline Zn deficiency $\ddagger$, $n$ and $\%$ & 5 & 3 \\
\hline $\begin{array}{l}\text { Serum vitamin } B_{12} \text { concentration } \\
(\mathrm{pmol} / \mathrm{l}) \text {, median and IQR }\end{array}$ & 123 & $97-160$ \\
\hline $\begin{array}{l}\text { Vitamin } \mathrm{B}_{12} \text { mild deficiency§, } \| \text {, } \\
n \text { and } \%\end{array}$ & 84 & 58 \\
\hline $\begin{array}{l}\text { Vitamin } \mathrm{B}_{12} \text { moderate/severe } \\
\text { deficiency } \|, \boldsymbol{\Pi}, n \text { and } \%\end{array}$ & 54 & 37 \\
\hline $\mathrm{Hb}$ concentration $(\mathrm{g} / \mathrm{l})$, mean and SD & 131 & 11 \\
\hline Anaemia**,$n$ and $\%$ & 9 & 6 \\
\hline Fe deficiency††, $n$ and \% & 53 & 36 \\
\hline Inflammation $\neq \ddagger, n$ and $\%$ & 31 & 20 \\
\hline
\end{tabular}

IQR, interquartile range (25-75th percentile).

${ }^{*}$ WHO 2006 reference population ${ }^{(23)}$.

†Vitamin A deficiency: serum retinol concentration $<0.70 \mu \mathrm{mol} / \mathrm{I}^{(19)}$

$\ddagger Z n$ deficiency: serum $\mathrm{Zn}$ concentration $<9.9 \mu \mathrm{mol} / /^{(20)}$.

$\S$ Vitamin $B_{12}$ mild deficiency: serum vitamin $B_{12}$ concentration $<133 \mathrm{pmol} / /^{(21)}$

$\| n 146$ for vitamin $\mathrm{B}_{12}$ and Fe deficiency.

TVitamin $B_{12}$ moderate/severe deficiency: serum vitamin $B_{12}$ concentration $<107 \mathrm{pmol} / \mathrm{I}^{(21)}$

${ }^{* *}$ Anaemia: $\mathrm{Hb}$ concentration $<115 \mathrm{~g} / \mathrm{l}$ for children aged $5-11$ years ${ }^{(22)}$ $\dagger+F e$ deficiency: serum ferritin concentration $<15 \mu \mathrm{g} / \mathrm{l}$ and soluble transferrin receptor concentration $>1.55 \mathrm{mg} / /^{(22)}$.

‡łInflammation: serum concentration of C-reactive protein $>5 \mathrm{mg} / \mathrm{l}$ and/or $\mathrm{a}_{1}$-acid glycoprotein $>1 \mathrm{~g} / \mathrm{/}^{(24)}$.

\section{Linear programming}

In Module 1 for each scenario twenty realistic diets were generated and, hence, no changes in parameters were needed. In Module 2, only diet contents of protein, vitamin C and thiamin were above $100 \%$ of the RNI for all three dietary scenarios in the best food pattern (Table 3). Furthermore, diet $\mathrm{Zn}$ and Fe contents achieved $>100 \%$ of the RNI in two scenarios: the maize and beans school lunch and the cassava school lunch. Only the cassava lunch achieved $>100 \%$ of the RNI in the Module 2 best food pattern for vitamin $\mathrm{B}_{6}$. The daily cost of the three scenarios ranged from 34 to $38 \mathrm{KES}$. The yellow cassava Module 2 best food pattern achieved $>100 \%$ of the RNI for the highest number of nutrients (Table 3; six out of thirteen nutrients). Problem nutrients, being $<100 \%$ of the RNI in the Module 2 best-case cassava scenario, were fat, Ca, riboflavin, niacin, folate, vitamin $\mathrm{B}_{12}$ and vitamin $\mathrm{A}$. A set of FBR was developed, including added fat 7 times/week, dairy products 7 times/week, grain and grain products 14 times/week, legumes 14 times/week, yellow cassava 5 times/week and vegetables 28 times/week. These recommendations ensured the worst-case scenario values for protein, vitamin C, vitamin $\mathrm{B}_{6}$, Fe and $\mathrm{Zn}$ achieved $>70 \%$ of the RNI, but those of fat, $\mathrm{Ca}$, riboflavin, niacin, folate, vitamin $\mathrm{B}_{12}$ and vitamin $\mathrm{A}$ remained less than $60 \%$ of their RNI (Table 4). The nutrientdense food items that contributed $\geq 20 \%$ to the intake of the problem nutrients were oil for fat, milk for riboflavin and vitamin $\mathrm{B}_{12}$, and kale/collard greens for vitamin $\mathrm{A}$. Frequency of these foods were increased with 7 servings/week. In addition, the hardly consumed foods chicken, beef and small dried fish were incorporated as nutrient-dense foods, although consumed by only three, two and one child(ren), respectively, in the age group 7-9 years. Portion sizes were estimated as median grams of the foods consumed by children in the total study population (age group of 5 to 13 years). Small dried fish was consumed only three times by the 5-13-year-old children and therefore the average portion size was used instead of median. All six nutrient-dense foods (oil, milk, kale/collard greens, chicken, beef and small dried fish) were added at various frequencies, individually and in combination, to the yellow cassava diet with FBR and for each combination a new set of FBR was developed and tested (Table 4). The addition of beef and chicken increased the nutrient adequacy only of niacin to at least $70 \%$ (78\% of the RNI) in the worst-case scenario. Small dried fish increased the nutrient adequacy for three nutrients to at least $70 \%$ of the RNI: Ca, niacin and vitamin $\mathrm{B}_{12}$. Beef and chicken were not combined with the dried fish because of negligible extra contribution of these foods to nutrient adequacy. Addition of five compared with two weekly servings of fish did not increase the number of nutrients achieving $>70 \%$ of the RNI, but would increase the daily cost of the diet. Also, the inclusion of more than five weekly servings of fish in the FBR would exceed the energy requirement.

\section{Final food-based recommendations}

The final set of FBR selected were: oil, 7 servings/week; dairy products, 7 servings/week; grain products, 14 servings/week; legumes, nuts or seeds, 14 servings/week; small dried fish, 2 servings/week; yellow cassava (provided as school lunch), 5 servings/week; and vegetables, 28 servings/week (Table 5). This set of FBR hypothetically ensures dietary adequacy at the population level for all nutrients except fat, riboflavin, folate and vitamin A. The increase of nutrient adequacy as a percentage of the RNI coverage of the optimized diet (yellow cassava diet with FBR with nutrient-dense foods) compared with the average food pattern without school lunch is shown in Fig. 1.

\section{Discussion}

We found that, compared with no school lunch or a school lunch with maize and beans, yellow cassava provided as a 
Table 2 Food groups and foods used for modelling as consumed by the study population of primary-school children ( $n$ 150) aged 7-9 years, Eastern Kenya, May-November 2012

\begin{tabular}{|c|c|c|c|c|c|}
\hline & $\begin{array}{l}\% \text { of children } \\
\text { consuming }\end{array}$ & $\underset{(\mathrm{g} / \mathrm{d})}{\text { Serving size }}$ & $\begin{array}{l}\text { Min. servings } \dagger \\
\text { (per week) }\end{array}$ & $\begin{array}{l}\text { Max. servingsł } \\
\text { (per week) }\end{array}$ & $\begin{array}{c}\text { Cost§ } \\
\text { (KES/100 g) }\end{array}$ \\
\hline Added fats & & 0 & 7 & & \\
\hline Oil, vegetable & 73 & 9 & 0 & 7 & 20 \\
\hline Added sugars & & 0 & 7 & & \\
\hline Sugar, brown & 20 & 14 & 0 & 4 & 12 \\
\hline Sugar, white & 13 & 9 & 0 & 3 & 12 \\
\hline Dairy products & & 0 & 7 & & \\
\hline Milk, cow's, fresh, boiled & 22 & 31 & 0 & 7 & 8 \\
\hline Grains \& grain products & & 7 & 21 & & \\
\hline Flour, maize, white & 65 & 165 & 0 & 7 & 6 \\
\hline Flour, wheat, refined & 14 & 97 & 0 & 5 & 7 \\
\hline Rice, refined & 8 & 83 & 0 & 2 & 12 \\
\hline Maize, grains, white, dried & 62 & 114 & 0 & 7 & 5 \\
\hline Legumes, nuts \& seeds & & 0 & 14 & & \\
\hline Beans, red, dried & 36 & 38 & 0 & 6 & 10 \\
\hline Beans, mung, dried & 5 & 48 & 0 & 1 & 10 \\
\hline Peas, pigeon, dried & 24 & 52 & 0 & 5 & 8 \\
\hline Peas, cow, dried & 8 & 54 & 0 & 2 & 7 \\
\hline Vegetables & & 0 & 28 & & \\
\hline Ŏnion, bulb, red & 68 & 4 & 0 & 7 & 10 \\
\hline Tomato & 62 & 30 & 0 & 7 & 5 \\
\hline Cabbage & 30 & 91 & 0 & 7 & 3 \\
\hline Kale/collard greens & 25 & 39 & 0 & 7 & 8 \\
\hline \multicolumn{6}{|c|}{ School lunches } \\
\hline \multicolumn{6}{|c|}{ Composites (mixed food groups) } \\
\hline Maize \& beans meal & 72 & 306 & 5 & 5 & 0 \\
\hline \multicolumn{6}{|c|}{ Starchy roots \& other starchy plant foods } \\
\hline Cassava, yellow $\|$ & 28 & 374 & 5 & 5 & 0 \\
\hline \multicolumn{6}{|l|}{ Nutrient-dense foods } \\
\hline \multicolumn{6}{|l|}{ Meat, fish \& eggs } \\
\hline Small fish, dried & 1 & 50 & 0 & 7 & 33 \\
\hline Beef & 1 & 55 & 0 & 7 & 36 \\
\hline Chicken & 2 & 45 & 0 & 7 & 49 \\
\hline
\end{tabular}

*Values are median serving sizes of the raw edible portions based on $24 \mathrm{~h}$ recalls. Median serving sizes for chicken and beef as well as mean portion size for fish were from 5-13-year-old children.

†Minimum frequencies were values in the 5th percentile of distribution.

¥Maximum frequencies were values in the 95th percentile of distribution.

$\S$ Mean costs in Kenyan Shilling (KES) per $100 \mathrm{~g}$ of edible portion, estimated from three different kind of shops or markets during

October 2012.

$\|$ Contains $394 \mu \mathrm{g} \beta$-carotene per $100 \mathrm{~g}$ boiled (fresh weight) based on own analysis ${ }^{(18)}$.

Table 3 Nutrient composition (as a percentage of the recommended nutrient intake (RNI)) of the three diets for the average* and the best† food pattern (Module 2) modelled using linear programming (Optifood) among primary-school children ( $n$ 150) aged 7-9 years, Eastern Kenya, May-November 2012

\begin{tabular}{|c|c|c|c|c|c|c|}
\hline & \multicolumn{2}{|c|}{ No school lunch } & \multicolumn{2}{|c|}{ Maize \& beans school lunch } & \multicolumn{2}{|c|}{ Yellow cassava school lunch } \\
\hline & $\begin{array}{c}\text { Average food } \\
\text { pattern } \\
\text { (\% of the RNI) }\end{array}$ & $\begin{array}{c}\text { Best food } \\
\text { patternt } \\
\text { (\% of the } \\
\text { RNI) }\end{array}$ & $\begin{array}{c}\text { Average food } \\
\text { pattern* } \\
\text { (\% of the RNI) }\end{array}$ & $\begin{array}{l}\text { Best food } \\
\text { patternt } \\
\text { (\% of the } \\
\text { RNI) }\end{array}$ & $\begin{array}{c}\text { Average food } \\
\text { pattern* } \\
\text { (\% of the RNI) }\end{array}$ & $\begin{array}{l}\text { Best food } \\
\text { pattern } \dagger \\
\text { (\% of the } \\
\text { RNI) }\end{array}$ \\
\hline Protein & 240 & 245 & 217 & 250 & 194 & 226 \\
\hline Fat & 45 & 43 & 49 & 44 & 55 & 50 \\
\hline $\mathrm{Ca}$ & 42 & 55 & 37 & 56 & 45 & 64 \\
\hline Vitamin C & 201 & 203 & 199 & 203 & 428 & 432 \\
\hline Thiamin & 122 & 117 & 143 & 137 & 151 & 145 \\
\hline Riboflavin & 38 & 46 & 48 & 61 & 37 & 50 \\
\hline Niacin & 50 & 55 & 61 & 71 & 56 & 66 \\
\hline Vitamin $\mathrm{B}_{6}$ & 69 & 73 & 85 & 95 & 137 & 147 \\
\hline Folate & 45 & 49 & 46 & 64 & 43 & 60 \\
\hline Vitamin $B_{12}$ & 3 & 19 & 4 & 10 & 4 & 10 \\
\hline Vitamin A & 17 & 19 & 17 & 19 & 47 & 49 \\
\hline $\mathrm{Fe}$ & 97 & 94 & 94 & 100 & 115 & 122 \\
\hline $\mathrm{Zn}$ & 95 & 99 & 98 & 113 & 89 & 104 \\
\hline Cost/d (KES) & 35 & 38 & 28 & 34 & 29 & 34 \\
\hline $\begin{array}{l}\text { No. of nutrients }>100 \% \\
\text { of the RNI }\end{array}$ & 3 & 3 & 3 & 5 & 5 & 6 \\
\hline
\end{tabular}

KES, Kenyan Shilling.

${ }^{*}$ Average food pattern = best diet within average food pattern closest to median food pattern of the population.

$\dagger$ †est food pattern = best diet deviating from average food pattern, but constrained by the minimum and maximum servings per week. 
Table 4 Results for the yellow cassava diet without and with food-based recommendations (FBR) including nutrient-dense foods, modelled using linear programming (Optifood) among primaryschool children $(n$ 150) aged 7-9 years, Eastern Kenya, May-November 2012

\begin{tabular}{|c|c|c|c|c|c|c|c|c|c|c|c|c|c|c|}
\hline & $\begin{array}{l}\text { Protein } \\
\text { (\% of the } \\
\text { RNI) }\end{array}$ & $\begin{array}{c}\text { Fat } \\
\text { (\% of the } \\
\text { RNI) }\end{array}$ & $\begin{array}{c}\text { Ca } \\
\text { (\% of the } \\
\text { RNI) }\end{array}$ & $\begin{array}{l}\text { Vitamin } \\
\text { C } \\
\text { (\% of the } \\
\text { RNI) }\end{array}$ & $\begin{array}{l}\text { Thiamin } \\
\text { (\% of the } \\
\text { RNI) }\end{array}$ & $\begin{array}{l}\text { Riboflavin } \\
\text { (\% of the } \\
\text { RNI) }\end{array}$ & $\begin{array}{l}\text { Niacin } \\
\text { (\% of the } \\
\text { RNI) }\end{array}$ & $\begin{array}{l}\text { Vitamin } \\
\mathrm{B}_{6} \\
\text { (\% of the } \\
\text { RNI) }\end{array}$ & $\begin{array}{c}\text { Folate } \\
\text { (\% of the } \\
\text { RNI) }\end{array}$ & $\begin{array}{c}\text { Vitamin } \\
\mathrm{B}_{12} \\
\text { (\% of the } \\
\text { RNI) }\end{array}$ & $\begin{array}{c}\text { Vitamin } \\
\text { A } \\
\text { (\% of the } \\
\text { RNI) }\end{array}$ & $\begin{array}{c}\text { Fe } \\
\text { (\% of the } \\
\text { RNI) }\end{array}$ & $\begin{array}{c}\mathrm{Zn} \\
\text { (\% of the } \\
\text { RNI) }\end{array}$ & $\begin{array}{c}\text { Cost }^{*} \\
\text { (KES/d) }\end{array}$ \\
\hline \multicolumn{15}{|l|}{ Yellow cassava diet without FBR } \\
\hline Best-case scenario & 236 & $58 \|$ & $65 \|$ & 432 & 158 & $51 \|$ & $67 \|$ & 148 & $61 \|$ & $10 \|$ & $49 \|$ & 131 & 106 & 37 \\
\hline Worst-case scenario & 161 & $31 "$ & 22 & 229 & 92 & $22 "$ & $38 "$ & 98 & $28 "$ & 3 & $30 "$ & 84 & 63 & 22 \\
\hline \multicolumn{15}{|l|}{ Yellow cassava diet with FBR† } \\
\hline Worst-case scenario & 219 & 49 & 58 & 432 & 125 & 43 & 57 & 130 & 56 & 10 & 49 & 121 & $87 \|$ & 33 \\
\hline \multicolumn{15}{|c|}{ Worst-case scenario results for nutrient-dense foods added to the yellow cassava diet with FBR } \\
\hline FBR + oil 7 servings/week & 213 & 65 & 61 & 432 & 136 & 48 & 63 & 141 & 59 & 10 & 49 & 118 & 136 & 34 \\
\hline FBR + milk 7 servings/week & 222 & 51 & 64 & 433 & 129 & 51 & 58 & 134 & 58 & 15 & 51 & 120 & 128 & 35 \\
\hline FBR + kale/collard greens 7 servings/week & 220 & 49 & 65 & 382 & 131 & 39 & 63 & 133 & 53 & 10 & 61 & 123 & 88 & 33 \\
\hline FBR + beef 2 servings/week & 231 & 53 & 59 & 432 & 132 & 48 & 64 & 137 & 58 & 21 & 50 & 123 & 98 & 38 \\
\hline FBR + beef 5 servings/week & 250 & 59 & 62 & 432 & 143 & 54 & $75 \pi$ & 147 & 59 & 37 & 51 & 125 & 115 & $46^{* *}$ \\
\hline FBR + chicken 2 servings/week & 229 & 50 & 59 & 432 & 128 & 46 & 62 & 135 & 57 & 12 & 51 & 121 & 91 & $39^{\star *}$ \\
\hline FBR + chicken 5 servings/week & 244 & 52 & 60 & 432 & 134 & 51 & $70 \pi$ & 142 & 58 & 15 & 54 & 121 & 98 & $48^{\star *}$ \\
\hline FBR + small dried fish§ 2 servings/week & 243 & 52 & $116 \pi$ & 432 & 132 & 50 & $70 \pi$ & 141 & 59 & $81 \pi$ & 49 & 124 & 103 & 37 \\
\hline FBR + small dried fish 5 servings/week & 283 & 58 & 205 Фी & 432 & 143 & 60 & 89ף & 159 & 62 & $188 \pi$ & 49 & 131 & 127 & $44^{\star *}$ \\
\hline \multicolumn{15}{|c|}{ Best-case scenario results for best optimized yellow cassava diet } \\
\hline FBR + small dried fish 2 servings/week & 286 & 59 & 211 & 431 & 148 & 61 & 90 & 160 & 63 & 195 & 49 & 131 & 129 & $45^{\star *}$ \\
\hline
\end{tabular}

RNI, recommended nutrient intake; KES, Kenyan Shilling

${ }^{*}$ Cost of the diet with or without FBR.

t\% of the RNI increased to at least $70 \%$ after FBR were applied.

fFBR: added fat, 7 servings/week; dairy products, 7 servings/week; grain and grain products, 14 servings/week; legumes, 14 servings/week; yellow cassava, 5 servings/week; and vegetables, 28 servings/week. Final set of FBR selected (best optimized diet).

Problem nutrients could not reach $100 \%$ of the RNI in the best-case scenario.

$\%$ of the RNI increased to at least $70 \%$ by adding the nutrient-dense food to the FBR.

${ }^{*}$ Daily cost raised above the 75 th percentile. 
school lunch can potentially improve vitamin A adequacy of the diet without lowering overall dietary quality. However, even though combining the yellow cassava school lunch with FBR improved the nutrient adequacy of the diet, it did not ensure adequate intakes of fat $(50 \%$ of the average requirement), riboflavin ( $55 \%$ of the RNI), folate ( $60 \%$ of the RNI) and vitamin A ( $47 \%$ of the RNI).

Table 5 Food-based recommendations (FBR) developed in the yellow cassava school lunch scenario optimized with nutrientdense foods and comparison with the average food pattern among primary-school children ( $n$ 150) aged 7-9 years, Eastern Kenya, May-November 2012

\begin{tabular}{|c|c|c|c|}
\hline $\begin{array}{l}\text { Scenario with yellow } \\
\text { cassava as } \\
\text { school lunch }\end{array}$ & $\begin{array}{l}\text { Average food } \\
\text { pattern* } \\
\text { (servings/ } \\
\text { week) }\end{array}$ & $\begin{array}{l}\text { With } \\
\text { FBR† } \\
\text { (servings/ } \\
\text { week) }\end{array}$ & $\begin{array}{c}\text { With FBR \& } \\
\text { optimized dietł } \\
\text { (servings/week) }\end{array}$ \\
\hline Added fats & 7 & 7 & 7 \\
\hline Dairy products & 0 & 7 & 7 \\
\hline Grains \& grain products & 7 & 14 & 14 \\
\hline Legumes, nuts \& seeds & 7 & 14 & 14 \\
\hline $\begin{array}{l}\text { Meat, fish \& eggs } \\
\text { (as small dried fish) }\end{array}$ & & & 2 \\
\hline $\begin{array}{l}\text { Starchy roots \& other } \\
\text { starchy plant foods } \\
\text { (as yellow cassava) }\end{array}$ & 5 & 5 & 5 \\
\hline Vegetables & 21 & 28 & 28 \\
\hline
\end{tabular}

${ }^{*}$ Results of Module 2 best diet within average food pattern of yellow cassava school lunch scenario.

†Results of Module 3 analysis of yellow cassava school lunch scenario with FBR including foods consumed by $\geq 5 \%$ of the children.

¥Results of Module 3 analysis of yellow cassava school lunch scenario with FBR including nutrient-dense foods consumed with low frequency or low quantity.
The low diversity of the foods in the monotonous diet (only sixteen different food items are consumed by more than $5 \%$ of the children), the low frequency and the small quantity of foods rich in nutrients consumed is a major limiting factor in the modelling. This suggests it will be a challenge to cover the nutrient gaps by adapting the local diet without introducing new nutrient-dense foods and/or radically modifying current food consumption patterns.

Remarkably, vitamin A remained a problem nutrient in our analyses and even the diet with yellow cassava, rich in pro-vitamin A, covered only $49 \%$ of the required vitamin A intake. Children selected for the present study represented the lowest end of the vitamin A status distribution in the area with $30 \%$ vitamin A deficiency. The diets of these children may therefore represent those that are low in vitamin A-rich foods compared with diets of other schoolchildren, which may explain why their recommended nutrient intake could not be fulfilled. Collard greens/kale provided the largest contribution to vitamin A intake, but quantities consumed were small, and for carotenoids both the bioavailability and retention due to long cooking is low ${ }^{(41)}$ leading to reduced intake of bioavailable vitamin A. In addition, we provided a conservative estimate of the potential increases in vitamin A intake as we used cassava varieties with an average $\beta$-carotene concentration of $5.4 \mu \mathrm{g} / \mathrm{g}$ (fresh weight) for raw cassava and $3.9 \mu \mathrm{g} / \mathrm{g}$ (fresh weight) for cooked cassava and applied a conservative conversion factor of 7:1. Another study found a higher impact of adding yellow cassava to

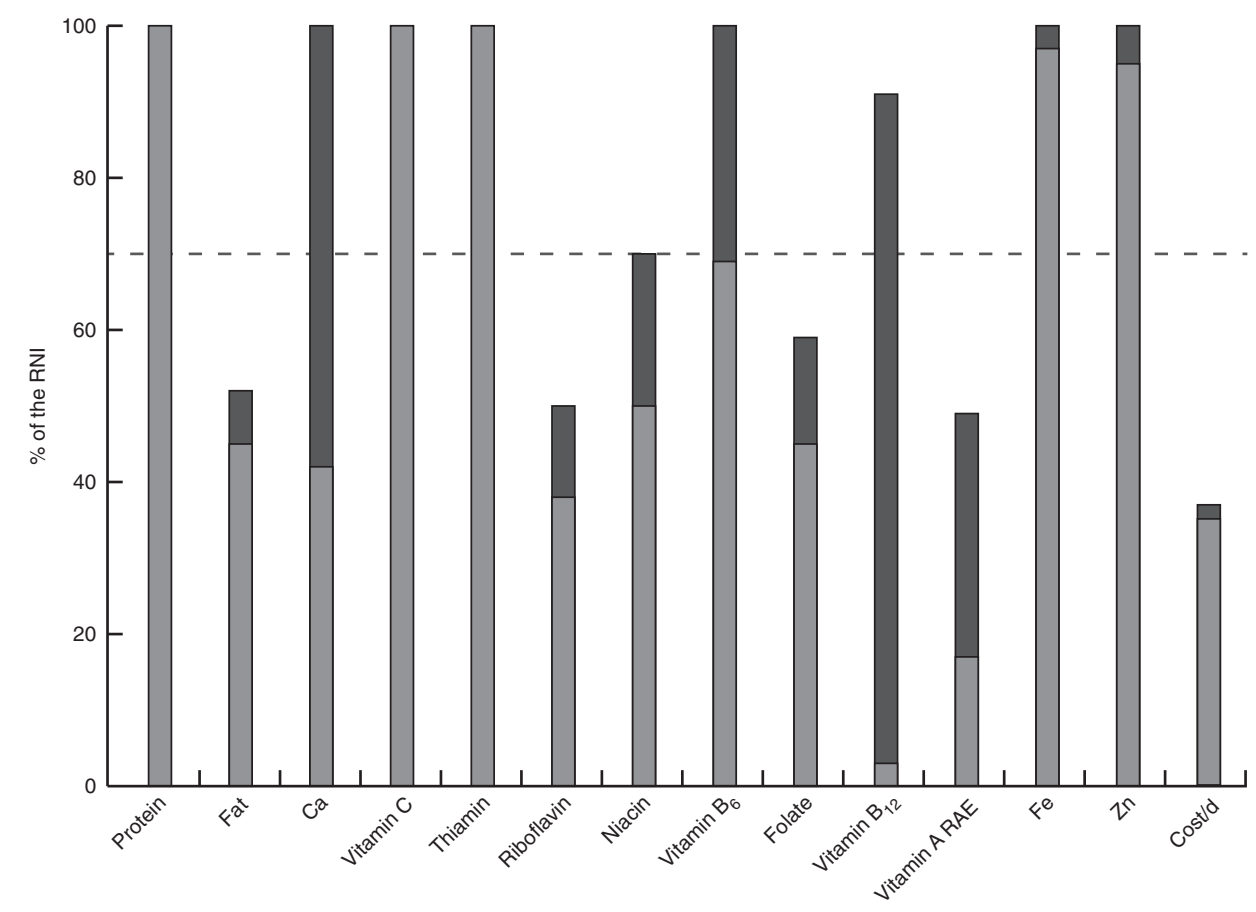

Fig. 1 Nutrient intake as a percentage of the recommended nutrient intake (RNI)* for the average food pattern ( $\square)$ and the optimized yellow cassava diet $+(\square)$ modelled using linear programming (Optifood) among primary-school children ( $n$ 150) aged 7-9 years, Eastern Kenya, May-November 2012. - - - - represents $70 \%$ of the RNI. *Values capped at $100 \%$; †final set of food-based recommendations selected (best optimized diet, in worst-case scenario). RAE, retinol activity equivalents 
the diet but used different modelling assumptions regarding concentration, cooking method and intake quantity $^{(4)}$.

In our study, Fe and $\mathrm{Zn}$ were not identified as problem nutrients and this corresponds with the few children being $\mathrm{Zn}$ deficient (3\%). Although 36\% of the children had $\mathrm{Fe}$ deficiency, only $6 \%$ had anaemia. Major food sources of $\mathrm{Fe}$ and $\mathrm{Zn}$ were maize, legumes and cassava, but animal foods were hardly consumed. For this reason, Fe bioavailability of $5 \%$, reflecting a vegetarian diet, was used $^{(28)}$, but the actual bioavailability of Fe in the diet may have been lower ${ }^{(42,43)}$. This might result in the identification of $\mathrm{Fe}$ as a problem nutrient. Also, food consumption studies among children 2-5 years old in Kenya and Nigeria showed that children consuming cassava as staple food are at risk for inadequate intake of $\mathrm{Fe}^{(6)}$. However, in our population cassava was not generally consumed as a staple food and other food sources ensured the adequacy of intake of Fe. Also, our study population is slightly older and the requirements for this older age group might be easier to achieve than for younger children.

The yellow cassava school lunch complemented with small dried fish ensured adequate dietary intake of Ca. Whole small fish including edible bones has proven to be a good source of Ca with a bioavailability comparable to that of milk $^{(44)}$. However, in our population only one child in the age group 7-9 years had consumed small fish. The reason schoolchildren do not consume small fish or fish in general is unknown. Since the research site was far from any source of fish, availability, affordability and taste could be constraints to consumption and reduce feasibility of this FBR.

Our study has limitations that should be acknowledged. First, the measurement of habitual dietary intake of groups remains a major challenge in dietary intake assessment ${ }^{(26)}$ and limitations of dietary data used as input for the Optifood analysis are related to weaknesses inherent to $24 \mathrm{~h}$ recalls. Major sources of systematic bias in the use of $24 \mathrm{~h}$ recall include under- or over-reporting of food intakes. To minimize bias, we used a systematic multiple-pass procedure and took precautions through training of interviewers, impromptu supervision to minimize reporting errors, proper calibration of instruments and random assignment of interviewers. Out-of-home food intake may have been omitted by mothers/caregivers and may have led to an underestimation of nutrient intake ${ }^{(45)}$. However, in this area, almost all meals are prepared and consumed at home and mothers/caregivers are fully involved in serving meals. Also, the presence of the children during the interviews meant they helped mothers/caregivers recall forgotten foods. Therefore, we believe that underestimation of food and thus nutrient intake was unlikely to have occurred.

We also assumed that the foods consumed out-ofschool in our population reflected the habitual diet of schoolchildren, implicitly anticipating that children in general do not take food to school and that food provided in school would not affect the amount of food consumed at home. However, the school meal can be shared with other household members or can substitute (at least partly) food normally consumed in the house ${ }^{(46)}$. This sharing occurs for take-home rations where children take home a given quantity of food on a regular basis ${ }^{(47)}$, but in our study the cassava lunch was consumed at school. Sharing may also happen between schoolchildren, but in our study children receiving the different lunches were physically separated. Substitution may also apply when meals are consumed at school, as in our study, and households opt to use the school meal as a substitute for food normally consumed at home as a cost-saving strategy. A study in rural Kenya did not find evidence that schoolchildren who received supplementary snacks at school reduced food intakes at home ${ }^{(48)}$. However, we observed during the preparation phase of the study that some children had taken food (consisting of maize and beans) from home to school for lunch, a habit they may have dropped when provided a school lunch. Our assumption that the food provided at school would not affect the food consumed outside school may have therefore led to a slight underestimation of the Optifood model parameters related to portion size and frequency of consumption, especially concerning maize and beans. As these foods are not major contributors to the nutrients identified as being in short supply, we assume a negligible effect on the identification of problem nutrients.

The cross-sectional survey captured a snapshot of dietary patterns and food cost/availability during only one agricultural season. As these vary per season, information on dietary intake in other seasons is necessary to evaluate applicability of our results through the year. Comparative analysis using dietary intake data from different seasons would be required to understand how FBR might change. It is also important to emphasize that the data used originated from a limited area in Kenya and are as such not representative for the whole of Kenya. Therefore, the extent to which the developed recommendations also apply to other areas in Kenya needs to be further assessed.

Finally, our results may be sensitive to assumptions used in defining model parameters. We used the International Zinc Nutrition Consultative Group's RNI ${ }^{(31)}$, which are below those recommended by the FAO/ $\mathrm{WHO}^{(28)}$. When we did a sensitivity analysis using the FAO/WHO's Zn RNI, Zn also became a problem nutrient for schoolchildren. This is not confirmed by the very low prevalence of $\mathrm{Zn}$ deficiency (3\%) in our population, indicating that the International Zinc Nutrition Consultative Group's RNI are likely the best to use. We assumed a low bioavailability of $\mathrm{Fe}(5 \%)$ based on the high consumption of unrefined cereals and legumes, and low consumption of animal-source foods. Doing so, Fe intake was not detected as below $70 \%$ of the RNI, even when low-nutrient-dense foods were used; assuming higher bioavailability would not change this finding. We included 
only foods consumed by $\geq 5 \%$ of the children: if we would have included foods consumed by $\geq 3 \%$ of the children, the number of foods in the food lists would have been increased slightly, however frequency of consumption of these foods was low and therefore it is unlikely that these foods would be selected in the FBR. In addition, including infrequently consumed foods may decrease the feasibility of implementing recommendations.

Our study shows that providing yellow cassava in a school lunch programme can ensure nutrient adequacy of the diet in our study area for nine out of thirteen micronutrients when promoted within a set of FBR. However, proposed recommendations will require changes in the diet (such as the consumption of small dried fish) and also imply additional changes to the school meal programme. Optifood modelling is theoretical by nature and therefore consultations with local stakeholders are very important to determine whether these modifications to typical dietary behaviour are realistic and feasible ${ }^{(10)}$ and recipes for the school meal programme incorporating these changes should be carefully developed and tested. However, even the best modelled diet could not meet the requirements for fat, riboflavin, folate and vitamin A. Additional interventions and solutions would be needed beyond promoting the consumption of nutrient-dense foods that are commonly consumed by the children to fully eliminate the risk of inadequate nutrient intakes in this population. Since the extent of the multiple micronutrient deficits in the modelled diets would be difficult to meet with a single intervention product, more biofortified crops could be introduced, or the introduction of yellow cassava could be integrated with approaches that encourage changes in the traditional diets as well as introduction of improved products such as fortified foods or improved nutrient supplements. Our study also showed that linear modelling of dietary intake data provides an excellent tool to evaluate and develop nutritional strategies for achieving better nutritional adequacy under local circumstances.

\section{Acknowledgements}

Acknowledgements: The authors thank all the parents, children and teachers of Muusini, Kithasyu and Thange primary schools for participation in this study. The contributions of Gloria Mbera, Harm Vermeylen and all other research assistants during data collection are highly appreciated. Financial support: This research was realized in the framework of the INSTAPA Project, funded by the European Union's Seventh Framework Programme (FP7/2007-2013) under grant agreement number 211484. The European Union had no role in the design, implementation, analysis or interpretation of the data. Conflict of interest: None of the authors had a conflict of interest. At the time of conducting the research, E.F.T. was working as a PhD candidate at Wageningen University. Currently she is affiliated with Harvestplus, International Center for Tropical Agriculture (CIAT), Cali, Colombia. I.D.B. is part of the team that develops the research programme for A4NH within the CGIAR. A.M.-B. is currently a grant holder for a study assessing the efficacy of yellow cassava on vitamin A status in pre-school children in Nigeria, funded by the International Food Policy Research Institute/HarvestPlus. Their funders had no role in the design, implementation, analysis or interpretation of the data. Authorship: The authors' responsibilities were as follows. E.F.T., A.M.-B., H.V. and I.D.B. designed the research. E.F.T., K.J.B.-v.d.B. and E.V.M. conducted the research. A.Y.D. supervised the biochemical analyses. E.F.T., K.J.B.v.d.B., E.L.F. and I.D.B. analysed data. E.F.T. and I.D.B. wrote the manuscript. E.F.T. and I.D.B. had primary responsibility for final content of the manuscript; and all authors read and approved the final manuscript. Ethics of buman subject participation: This study was conducted according to the guidelines laid down in the Declaration of Helsinki and all procedures involving human subjects were approved by ethical committees at Kenyatta National Hospital in Nairobi, Kenya and Wageningen University in the Netherlands. The study was registered (clinicaltrials.gov: NCT01614483) and written consent was obtained from parents and children before the start of the trial.

\section{References}

1. Bouis HE, Hotz C, McClafferty B et al. (2011) Biofortification: a new tool to reduce micronutrient malnutrition. Food Nutr Bull 32, 1 Suppl., S31-S40.

2. Chávez AL, Sánchez T, Jaramillo G et al. (2005) Variation of quality traits in cassava roots evaluated in landraces and improved clones. Euphytica 143, 125-133.

3. Saltzman A, Birol B, Bouis HE et al. (2013) Biofortification: progress toward a more nourishing future. Glob Food $\operatorname{Sec} \mathbf{2}$, 9-17.

4. Katz JM, la Frano MR, Winter CK et al. (2013) Modelling potential $\beta$-carotene intake and cyanide exposure from consumption of biofortified cassava. J Nutr Sci 2 , e6

5. Maziya-Dixon B, Kling JG, Menkiar A et al. (2013) Genetic variation in total carotene, iron and zinc contents of maize and cassava genotypes. Food Nutr Bull 21, 419-422.

6. Gegios A, Amthor R, Maziya-Dixon B et al. (2010) Children consuming cassava as a staple food are at risk for inadequate zinc, iron, and vitamin A intake. Plant Foods Hum Nutr 65, 64-70.

7. Joy EJM, Ander EL, Young SD et al. (2014) Dietary mineral supplies in Africa. Physiol Plant 151, 208-229.

8. Ferguson EL, Darman N, Briend A et al. (2004) Food-based dietary guidelines can be developed and tested using linear programming analysis. J Nutr 134, 951-957.

9. Skau JK, Bunthang T, Chamnan C et al. (2014) The use of linear programming to determine whether a formulated complementary food product can ensure adequate nutrients for 6- to 11-month-old Cambodian infants. Am J Clin Nutr 99, 130-138. 
10. Food and Nutrition Technical Assistance III Project (2013) Summary Report: Development of Evidence Based Dietary Recommendations for Children, Pregnant Women and Lactating Women Living in the Western Highlands in Guatemala. Washington, DC: FBI360/FANTA.

11. World Food Programme (2013) State of School Feeding Worldwide 2013. Rome: WFP.

12. Van Stuijvenberg ME (2005) Using the school feeding system as a vehicle for micronutrient fortification: experience from South Africa. Food Nutr Bull 26, 2 Suppl. 2, S213-S219.

13. Gelli A, Espejo F, Jing S et al. (2014) Putting It All Together: Aggregating Impacts of School-Feeding Programmes on Education, Health and Nutrition: Two Proposed Methodologies. WIDER Working Paper no. 2016/036. Helsinki: United Nations University, World Institute for Development Economics Research.

14. Kristjansson EA, Robinson V, Petticrew M et al. (2007) School feeding for improving the physical and psychosocial health of disadvantaged elementary school children. Cochrane Database Syst Rev issue 1, CD004676.

15. Neumann CG, Bwibo NO \& Murphy SP (2003) Animal source foods improve dietary quality, micronutrient status, growth and cognitive function in Kenyan school children: background, study design and baseline findings. J Nutr $\mathbf{1 3 3}$, 11 Suppl. 2, 3941S-3949S.

16. Siekmann JH, Allen LA, Bwido NO et al. (2003) Kenyan school children have multiple deficiencies, but increased plasma vitamin B-12 is the only detectable micronutrient response to meat or milk supplementation. J Nutr 133, 11 Suppl. 2, 3972S-3980S.

17. Murphy SP, Gewa C, Liang LJ et al. (2003) School snacks containing animal source foods improve dietary quality for children in rural Kenya. J Nutr 133, 11 Suppl. 2, 3950S-3956S.

18. Talsma EF, Brouwer ID, Verhoef H et al. (2016) Biofortified yellow cassava and vitamin A status of Kenyan children: a randomized controlled trial. Am J Clin Nutr $\mathbf{1 0 3}$ 258-267.

19. Sommer A \& Davidson FR (2002) Assessment and control of vitamin A deficiency: the Annecy Accords. J Nutr 132, 9 Suppl., 2845S-2850S.

20. De Benoist B, Darnton-Hill I, Davidsson L et al. (2007) Conclusions of the Joint WHO/UNICEF/IAEA/IZiNCG Interagency Meeting on Zinc Status Indicators. Food Nutr Bull 28, 3 Suppl., S480-S484.

21. Beckman Coulter (2011) Access Immunoassay Systems, vitamin B12 REF 33000, Product Insert A89094B. www. beckmancoulter.com (accessed October 2014).

22. World Health Organization/UNICEF/United Nations University (2001) Iron Deficiency Anaemia: Assessment, Prevention, and Control. A Guide for Programme Managers. WHO/NHD/01.3. Geneva: WHO.

23. de Onis M, Onyango AW \& Van den Broeck J (2004) Measurement and standardization protocols for anthropometry used in the construction of a new international growth reference. Food Nutr Bull 25, 1 Suppl., S27-S36.

24. Thurnham DI, McCabe GP, Northrop-Clewes CA et al. (2003) Effects of subclinical Infection on plasma retinol concentrations and assessment of prevalence of vitamin A deficiency: meta-analysis. Lancet 362, 2052-2058.

25. Conway JM, Ingwersen LA, Vinyard BT et al. (2003) Effectiveness of the USDA's Five-Step Multiple-pass method to access food intake in obese and nonobese women. $A m \mathrm{~J}$ Clin Nutr 77, 1171-1178.

26. Gibson RS \& Ferguson EL (2008) An Interactive 24-Hour Recall for Assessing the Adequacy of Iron and Zinc Intakes in Developing Countries. HarvestPlus Technical Monograph Series no. 8. Washington, DC and Cali: International Food Policy Research Institute and International Center for Tropical Agriculture.
27. Food and Agriculture Organization of the United Nations (2004) Human Energy Requirements. Report of a Joint FAO/WHO/UNU Expert Consultation. FAO Food and Nutrition Technical Report Series no. 1. Rome: FAO/WHO/UNU.

28. Food and Agriculture Organization of the United Nations (2004) Human Vitamin and Mineral Requirements. Report of a Joint FAO/WHO Expert Consultation, Bangkok, Thailand, 21-30 September 1998. Geneva: WHO.

29. Food and Agriculture Organization of the United Nations/ World Health Organization/United Nations University (2007) Protein and Amino Acid Requirements in Human Nutrition. Report of a Joint FAO/WHO/UNU Expert Consultation. WHO Technical Report Series no. 935. Geneva: WHO.

30. Food and Agriculture Organization of the United Nations (2010) Fats and Fatty Acids in Human Nutrition. Report of an Expert Consultation. FAO Food and Nutrition Paper no. 91. Rome: FAO.

31. International Zinc Nutrition Consultative Group (IZiNCG), Brown KH, Rivera JA et al. (2004) International Zinc Nutrition Consultative Group (IZiNCG) technical document $\# 1$. Assessment of the risk of zinc deficiency in populations and options for its control. Food Nutr Bull 25, 1 Suppl. 2, S91-S204.

32. Sehmi JK (1993) National Food Composition Tables and the Planning of Satisfactory Diets in Kenya. Nairobi: Government Press.

33. Wolmarans P, Danster N, Dalton A et al. (2010) Condensed Food Composition Tables for South Africa. Cape Town: Medical Research Council.

34. Barikmo I, Ouattara F \& Oshaug A (2004) Table de Composition des Aliments du Mali. Oslo: Akerhus University College.

35. West CE, Pepping F \& Temalilwa CR (1988) The Composition of Foods Commonly Eaten in East Africa. Wageningen: Wageningen University.

36. Calloway DH, Murphy SP \& Bunch S (1994) User's guide to the international mini-list nutrient database in World Food Dietary Assessment System, 1994. Department of Nutritional Sciences, University of California at Berkeley, Berkeley, CA; available at www.fao.gov/infoods (accessed March 2014).

37. US Department of Agriculture (2007) National Nutrient Database for Standard Reference, Release 25. Washington, DC: USDA, Agricultural Research Service.

38. US Department of Agriculture (2007) USDA Table of Nutrient Retention Factors, Release 6. Washington, DC: USDA, Agricultural Research Service; available at Nutrient Data Laboratory Home Page, http://www.ars.usda.gov/ba/ bhnrc/ndl

39. West CE, Eilander A \& van Lieshout M (2002) Consequences of revised estimates of carotenoid bioefficacy for dietary control of vitamin A deficiency in developing countries. $J$ Nutr 132, 9 Suppl., 2920S-2926S.

40. La Frano MR, Woodhouse LR, Burnett DJ et al. (2013) Biofortified cassava increases $\beta$-carotene and vitamin A concentrations in the TAG-rich plasma layer of American women. Br J Nutr 110, 310-320.

41. De Pee S, West CE, Permaesih D et al. (1998) Orange fruit is more effective than are dark-green, leafy vegetables in increasing serum concentrations of retinol and $\beta$-carotene in schoolchildren in Indonesia. Am J Clin Nutr 68, 1058-1067.

42. Beiseigel JM, Hunt JR, Glahn RP et al. (2007) Iron bioavailability from maize and beans: a comparison of human measurements with Caco-2 cell and algorithm predictions. Am J Clin Nutr 86, 388-396.

43. Donangelo CM, Woodhouse LR, King SM et al. (2003) Iron and zinc absorption from two bean (Phaseolus vulgaris L.) genotypes in young women. J Agric Food Chem 51, 5137-5143.

44. Hansen M, Thilsted SH, Sandström B et al. (1998) Calcium absorption from small soft-boned fish. $J$ Trace Elem Med Biol 12, 148-154. 
45. Gewa CA, Murphy SP \& Neumann CG (2007) Out-of-food intake is often omitted from mother's recalls of school children's intake in rural Kenya. J Nutr 137, 2154-2159.

46. Masset E \& Gelli A (2013) Improving community development by linking agriculture, nutrition and education: design of a randomised trial of 'home-grown' school feeding in Mali. Trials 14, 55.
47. Kazianga H, de Walque D \& Alderman H (2008) Educational and Health Impact of Two School Feeding Schemes: Evidence from a Randomized Trial in Rural Burkina Faso. Washington, DC: The World Bank.

48. Gewa CA, Murphy SP, Weiss RE et al. (2013) A school-based supplementary food programme in rural Kenya did not reduce children's intake at home. Public Health Nutr 16, 713-720. 